\title{
SAFETY AND RELIABILITY OF CARBON-PEEK PLATE FOR THE TREATMENT OF DISTAL RADIUS FRACTURES: A REVIEW OF THE LITERATURE
}

\author{
Michela Saracco ${ }^{1}$, Camillo Fulchignoni ${ }^{1}$, Calogero Velluto ${ }^{1}$, Lorenzo Rocchi ${ }^{1}$ \\ 1 Department of Orthopaedics - Hand Surgery Unit, Fondazione Policlinico Universitario A. Gemelli IRCCS, Roma - Università Cattolica del Sacro Cuore \\ Keywords: distal radius fracture, carbon-fiber-reinforced PEEK plate, open reduction and internal fixation, carbon fibers materials \\ https://doi.org/10.52965/001c.28362
}

\section{Orthopedic Reviews}

Vol. 13, Issue 1, 2021

\section{Introduction}

Distal radius fractures are one of the most common injuries. Open reduction and internal fixation (ORIF) are the most diffused between surgical treatments. Carbon-fiber reinforced (CFR) polyetheretherketone (PEEK) plates have been proposed to prevent effects linked to stainless steel or titanium alloy traditional plates, such as radio-opacity, mismatch of bone-plate elasticity modulus, corrosion, limited fatigue life, osseointegration.

\section{Objective}

This review aims to evaluate the actual safety and reliability of CFR- PEEK plates to treat distal radius fractures.

\section{Methods}

Electronic databases PubMed, Google Scholars, and Cochrane Library were searched in December 2020. Eligible studies were published in peer-reviewed journals. Three authors independently selected relevant articles and discussed those. Searching identified 13 titles and abstracts, 11 manuscripts were considered eligible for the full-text analysis. Of these 11 papers, 7 studies were included in our review.

\section{Results}

215 patients were analyzed in this systematic review. The mean age of enrolled patients was 52,8 years. $34 \%$ were males and $66 \%$ were females. Fractures were classified according to AO/ASIF classification system. We reported 12 cases of complications specific to this device, such as intraoperative plate and screws rupture, erosive flexor tendons synovitis, and loosening.

\section{Conclusion}

CFR-PEEK distal radius plates are potentially an alternative to traditional ones. But we believe that the use of this device does not entail a significant advantage in the treatment of distal radius fractures, as safe and low-cost traditional devices are available. Further comparative studies are needed to demonstrate the superiority of carbon devices.

\section{INTRODUCTION}

Distal radius fractures are one of the most common injuries, especially in elderly female patients. Osteoporosis is the most important risk factor. ${ }^{1}$

Open reduction and internal fixation (ORIF) are the most diffused between surgical treatments, particularly with a

\footnotetext{
a Corresponding author:

Dr. Michela Saracco

Largo Francesco Vito, 1

00168 Rome (Italy)

+393388679796

michelasaracco@gmail.com
} 
volar approach. This surgical approach has become the standard of care in the last decade. It reduces the incidence of tendinitis and tendon rupture in comparison with the dorsal wrist approach, allowing a stable fixation with low complication rates in the vast majority of distal radius fractures. ${ }^{2-4}$ The development of angular stable plating furtherly reduced complications such as loss of reduction. This system firstly thought for osteoporotic bone, permits to restore articular congruity with better precision preventing osteoarthritis, allowing early rehabilitation and fast recovery. ${ }^{5-7}$

Traditionally, those plates are made of stainless steel or titanium alloys, with disadvantages such as radio-opacity, mismatch of bone-plate elasticity modulus, corrosion, limited fatigue life, osseointegration. ${ }^{8}$ To prevent effects linked to those characteristics, carbon-fiber-reinforced (CFR) polyetheretherketone (PEEK) plates have been proposed (Figure 1). Those implants have proven excellent biocompatibility, with very low release of debris in vitro and in vivo, and better biomechanical results in bending and fatigue stress compared to other metal devices. 9,10 The role of the polymer matrix that surrounds the carbon fibers is to prevent direct contact with living cells, avoiding a possible inflammatory reaction. ${ }^{11}$ In fact, the main cause of acute or chronic inflammatory response seems to be the presence of debris originating from carbon fibers. ${ }^{12-14}$

The main clinical advantages of CFR-PEEK plates are: radio-transparency of the material that facilitate intra-operative reduction and bone healing assessment; absence of artifacts on magnetic resonance imaging (MRI) and computed tomography (CT); absence of corrosion and cold-welding phenomenon, making it easier to proceed to plate removal (Figure 2). 15

In addition to the already cited possibility to cause an inflammatory reaction in case of direct contact between carbon fibers and cells - different cases have been described in other surgeries using carbon fibers materials such as knee prosthesis, cages for back surgery, or acetabular components ${ }^{16-19}$ - main disadvantages of CFR-PEEK implants seem to be: weakness to deformation and lower load to failure compared to traditional plates that might lead to an easier implant breakage, eventual PEEK allergies, and higher costs. ${ }^{20}$

To our knowledge, only one comparative study between traditional plates and CFR-PEEK plates for the distal radius fracture treatment has been published ${ }^{21}$; no other review discussing the use of this kind of implant in the distal upper extremity is present in the literature. Our proposed review aims to determine outcomes and complications associated with CFR-PEEK plates for distal radius fracture treatment.

\section{METHODS}

Electronic literature research was carried out on PubMed, Google Scholars, and Cochrane Library, in line with the PRISMA statement. ${ }^{22}$ To find relevant studies, the authors used the keywords: "Distal Radius Carbon Plate CFR-PEEK" and their MeSH terms in any possible combination. Three authors independently selected relevant papers and subsequently discussed those. The reference lists of all relevant publications were screened for additional pertinent articles,

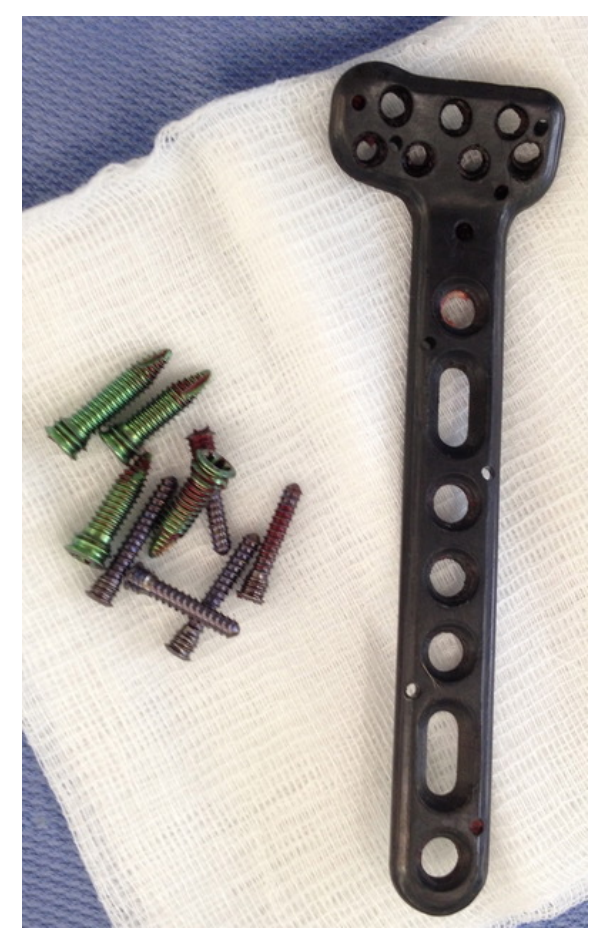

Figure 1. Postoperative view of a carbon-fiberreinforced (CFR) polyetheretherketone (PEEK) plate and screws after surgical removal.

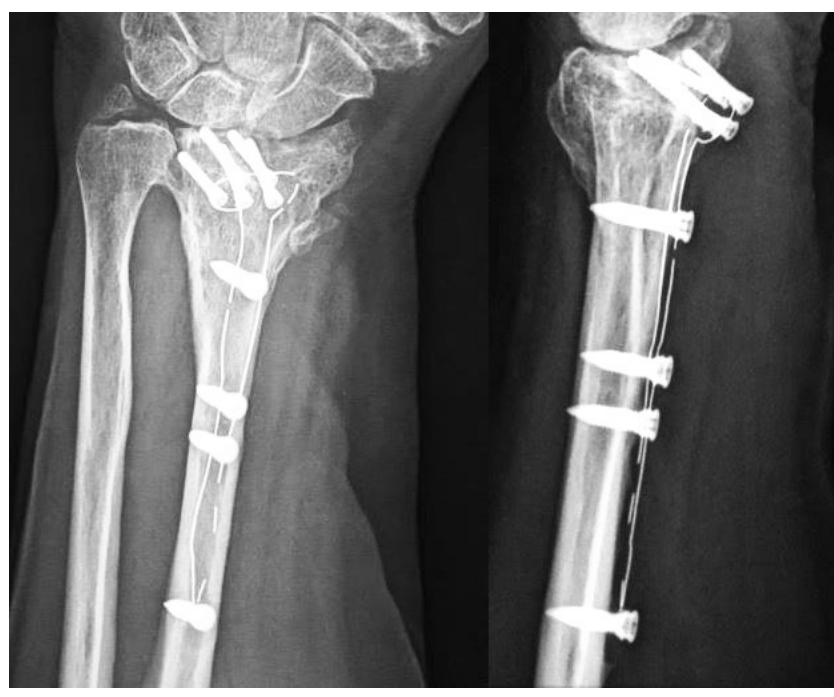

Figure 2. X-ray showing a carbon-fiber-reinforced (CFR) polyetheretherketone (PEEK) wrist plate in situ 4 months after ORIF.

whereas papers with patients' duplications were excluded. Searches were updated to December 2020: seven articles were finally selected, among which six are in English and one in German- translated by a professional translator before analysis. ${ }^{23}$ After screening 13 titles and abstracts, 11 manuscripts were considered eligible for the full-text analysis. Of these 11 papers, 7 studies were included in our review, considering that four articles by Tarallo et al. refer to the same cohort of patients (only the latest one was 
Table 1. Demographics of the studies included in our review.

\begin{tabular}{|c|c|c|c|c|c|c|}
\hline $\begin{array}{l}\text { Study } \\
\text { (Excluding } \\
\text { case } \\
\text { reports) }\end{array}$ & Cases & $\begin{array}{l}\text { Mean } \\
\text { age }\end{array}$ & $\begin{array}{l}\text { Follow- } \\
\text { Up } \\
\text { (months) }\end{array}$ & Type of fracture (AO-OTA) & $\begin{array}{l}\text { Clinical } \\
\text { evaluations }\end{array}$ & $\begin{array}{l}\text { Union } \\
\text { time } \\
\text { (weeks) }\end{array}$ \\
\hline $\begin{array}{l}\text { Behrendt } \\
2015\end{array}$ & 26 & 59.3 & 12 & $23-A 2-C$ & $\begin{array}{l}\text { DASH-score, } \\
\text { Mayo-wrist } \\
\text { Score, VAS, } \\
\text { ROM }\end{array}$ & - \\
\hline $\begin{array}{l}\text { Di Maggio } \\
2017\end{array}$ & 64 & 56.8 & 12 & $\begin{array}{l}9 \text { cases } 23-B 1,13 \text { cases } 23-B 2,15 \\
\text { cases } 23-B 3,10 \text { cases } 23-C 1,7 \text { cases } \\
23-C 2,10 \text { cases } 23-C 3\end{array}$ & $\begin{array}{l}\text { Modified } \\
\text { Mayo-Wrist } \\
\text { Score }\end{array}$ & 5.8 \\
\hline $\begin{array}{l}\text { Perugia } \\
2017\end{array}$ & 15 & $\begin{array}{l}56.8 \\
\pm 7.1\end{array}$ & 15.7 & $23-B / C$ & $\begin{array}{l}\text { ROM, DASH- } \\
\text { score, VAS, } \\
\text { Grip strength }\end{array}$ & - \\
\hline $\begin{array}{l}\text { Allemann } \\
2019\end{array}$ & 10 & 53.3 & 12 & $23-B$ & ROM & - \\
\hline $\begin{array}{l}\text { Tarallo } \\
2020\end{array}$ & 110 & 58 & 48 & $\begin{array}{l}14 \text { cases } 23-A 3,33 \text { cases } 23-B 3,18 \\
\text { cases } 23-C 1,30 \text { cases } 23-C 2,15 \text { cases } \\
23-C 3\end{array}$ & - & - \\
\hline
\end{tabular}

included in our review). ${ }^{20,24-26}$ Merolli et al. published a letter to the editor in 2015 and the related case report in 2016. Consequently, only the latter was included. ${ }^{11,12} \mathrm{Re}-$ searches included in this review have been performed following the ethical standards laid down in the 1964 Declaration of Helsinki and its later amendments.

\section{RESULTS}

\section{EPIDEMIOLOGICAL DATA}

Overall, 215 patients were analyzed in this systematic review. The mean age of enrolled patients was 52,8 years. 73 (34\%) were males and 142 (66\%) were females.

All patients were affected by distal radius fracture and underwent ORIF with CFR-PEEK plate, except for a 26-yearold female patient reported by Guzzini et al. ${ }^{27}$ She was affected by stage I Kienbock's Disease and underwent to distal radius osteotomy core decompression fixed with CarbonPEEK plate.

\section{CLINICAL OUTCOMES AND STUDIES ANALYSIS (TABLE 1)}

In 2015 Berendht et al. reported 14 patients, 3 male and 11 females, with type 23-A2-C distal radius fracture according to AO/ASIF classification system, treated with ORIF with a PEEK plate system (2.7 mm Distal Radius Plate). ${ }^{28}$ The mean age was 59,3 years (min and max not reported). Subsequently, patients were evaluated radiographically with X-rays and clinically with DASH-score, Mayo-wrist score, VAS, and ROM. The mean follow-up was 12 months (min and max not reported). No patients had peri- or postoperative complications. In 2016 Merolli et al. published a case report of a female patient who reported an aggressive erosive flexor tendons synovitis after 11 months of ORIF with a CFR-PEEK plate. ${ }^{12}$ This has been the only case reported in the literature until now. ${ }^{23}$

Dimaggio et al., in 2017, reported 64 patients treated with CFR-PEEK implants. 26 males and 38 females. The mean age was 56,8 years (min 23 years - max 84 years). Among these, 9 patients were affected by distal radius fracture type 23-B1 according to AO/ASIF classification system, 13 patients were affected by $23-B 2,15$ patients by $23-B 3,10$ patients by $23-\mathrm{C} 1,7$ patients by $23-\mathrm{C} 2$, and 10 patients by $23-\mathrm{C} 3{ }^{28}$ Moreover, all patients were evaluated radiographically by CT during follow-up. Clinically, patients were evaluated by the Mayo modified score. In total, they reported 1 aseptic loosening at 5 months as an adverse event. Consequently, the CRF-PEEK plate was removed. ${ }^{15}$

Perugia et al., in 2017, published a retrospective study evaluating 15 patients treated with carbon PEEK plate. There were 5 males and 10 females. The mean age was 56.8 \pm 7.1 years (range $32-71$ years) at the time of surgery. 11 patients $(73.3 \%)$ had involvement of the non-dominant arm. Fractures were classified according to AO/ASIF classification system. There were two type B1, one type B2, three type $\mathrm{B} 3$, five type $\mathrm{C} 1$, one type $\mathrm{C} 2$, three type $\mathrm{C} 3$.

All patients were clinically evaluated by ROM, DASH, VAS, Grip Strength with a mean follow-up of 15.7 months (min: 12 months; max: 19 months). None of the 15 patients had postoperative complications. ${ }^{21}$

Allemann et al., in 2019, reported 10 patients all affected by type B fracture, treated with CFR-PEEK plate (Inc. Icotec, Altstätten, Switzerland). These patients were $53.3 \pm 16.6$ years old and the male/female ratio was 60:40. Patients were radiographically evaluated by X-ray and $\mathrm{CT}$, and only ROM was clinically evaluated. The intraoperative rupture of the screw head in two screws has been documented, but this did not lead to any complication. No other peri- or postoperative complications were described. ${ }^{29}$

Guzzini et al., in 2019, published a case report concerned about a 26-years-old female patient affected by stage I Kienbock's disease and treated with distal radius osteotomy and fixed with a Carbon-PEEK plate. Patient follow-up was performed with clinical evaluation (ROM analysis, VAS 
Table 2. Incidence and type of complications occurred.

\begin{tabular}{|c|c|c|c|c|c|}
\hline Complication & Study & $\begin{array}{l}\text { Study } \\
\text { cases }\end{array}$ & $\begin{array}{l}\text { Number of } \\
\text { complications }\end{array}$ & $\begin{array}{l}\text { Time from } \\
\text { surgery } \\
\text { (months) }\end{array}$ & Second surgery \\
\hline $\begin{array}{l}\text { Aggressive erosive flexor } \\
\text { tendons sinovytis }\end{array}$ & $\begin{array}{l}\text { Merolli } \\
2016 \\
\end{array}$ & 1 & 1 & 11 & Plate removal \\
\hline Aseptic loosening & $\begin{array}{l}\text { Di } \\
\text { Maggio } \\
2017\end{array}$ & 64 & 1 & 5 & Plate removal \\
\hline $\begin{array}{l}\text { Intraoperative screws } \\
\text { rupture }\end{array}$ & $\begin{array}{l}\text { Allemann } \\
2019\end{array}$ & 10 & 1 & - & - \\
\hline Infection & $\begin{array}{l}\text { Tarallo } \\
2020\end{array}$ & 110 & 1 & 1 & $\begin{array}{l}\text { Plate removal, } \\
\text { debridement, new } \\
\text { synthesis }\end{array}$ \\
\hline FLP rupture & $\begin{array}{l}\text { Tarallo } \\
2020\end{array}$ & 110 & 1 & 12 & Surgical reconstruction \\
\hline Extensor tendinitis & $\begin{array}{l}\text { Tarallo } \\
2020\end{array}$ & 110 & 2 & $5 ; 10$ & Plate removal \\
\hline $\begin{array}{l}\text { Intraoperative plate } \\
\text { rupture }\end{array}$ & $\begin{array}{l}\text { Tarallo } \\
2020\end{array}$ & 110 & 5 & - & $\begin{array}{l}\text { Synthesis with new PEEK } \\
\text { plate }\end{array}$ \\
\hline
\end{tabular}

score, Quick Dash Score), wrist radiographs, and wrist MRI. Return to sporting activity was conceded after 3 months without any complication. 27

Lastly, Tarallo et al. published a retrospective study including 110 patients treated for distal radius fracture using a volar fixed-angle plate DiPHOS-RM (Lima Corporate, Udine, Italy). All CFR-PEEK plates were implanted between May 2012 and December 2017. 33 males and 77 females were enrolled. The mean age was 58 years old (min: 23 years; max:86 years) and the mean follow-up was 48 months (min: 14 months; max: 21 months). Among these, there were 14 cases of A3 fracture according to the AO Classifications system, 33 cases of $\mathrm{B} 3,18$ cases of $\mathrm{C} 1,30$ cases of $\mathrm{C} 2$, and 15 cases of $\mathrm{C} 3$. All patients, except 10 , were evaluated with a mean follow-up of four years (range 14-81 months). Patients were radiographically and clinically evaluated at 1 , 2,3 , and 12 months and then re-evaluated until complete healing. Finally, the authors reported one case of flexor pollicis longus (FPL) rupture one year after surgery, one case of infection, two cases of extensor tendonitis, and 5 cases of plate failure. $^{26}$

\section{COMPLICATIONS (TABLE 2)}

A further distinction should be made between complications. There are complications related to perioperative surgical technique factors, independent of the plate's biomechanical structure, and ones related to the plate itself.

Dimaggio et al. reported one aseptic loosening at 5 months, while Tarallo et al. described one case of FPL rupture one year after surgery and two cases of extensor tendinitis: we consider these as generic complications. ${ }^{15,26}$ Complications related to the type of materials used are instead those reported by Merolli et al. They described an aggressive flexor tendons synovitis consequently to the release of carbon fibers due to the lesion of the device's coating during its implantation. ${ }^{12}$ Tarallo et al. documented some cases of plate rupture. ${ }^{26}$ Allemann et al. reported intraoperative breakage of the screw head. ${ }^{29}$

\section{DISCUSSION}

Fractures of the distal radius are among the most common ones in adults, and their incidence continues to rise as the average age of the population increases. Most postmenopausal women are affected due to osteoporosis. The initial treatment of non-displaced fractures may be conservative, although not infrequently, secondary displacement that requires surgical procedure are observed. ORIF with plate and screws is necessary in displaced and / or intraarticular fractures. To date, numerous types of both dorsal and volar plates are available on the market. Industries produce every year new devices that are increasingly low profile and easy to install. With this goal, carbon plates have been introduced to the market. However, they had a low diffusion, likely due to the higher costs of production and not widespread distribution. Polyetheretherketone reinforcedcarbon fiber composite radiolucent devices are characterized by complete radiolucency, which allows viewing the progress of the bone healing optimally.

Furthermore, they are thin and light to ensure a minor impact on the biomechanics of a complex district such as the wrist. Moreover, these devices have some other advantages, such as low artifacts on MRI and the possibility of being designed with more appropriate strength, toughness, stiffness, or better fatigue resistance. ${ }^{9,10}$ PEEK devices are used in orthopedic surgery in different anatomic districts, such as the proximal humerus, distal tibia, and vertebral surgery. Despite this, there is little literature regarding their use for the treatment of distal radius fractures. Even in the presence of logical indications for their use, many doubts remain about the risk of local complications, even very ag- 
gressive ones.

In the manuscripts selected for this review, the first complication noted is tendons inflammation or damage. As many as two authors reported extensor tendons synovitis.

Tarallo et al., on a total of 110 patients studied, reported 2 cases of extensor tendons synovitis. ${ }^{26}$ We agree with the authors in believing that this complication is probably due to an error in the surgical technique and not to the implanted devices. The implantation of screws that are too long from volar to dorsal implies a repeated inflammatory stimulus on the extensor tendons during their sliding. And therefore, this is a possible complication with implanted devices of any material available on the market. Tarallo et al. also described 1 case of rupture of the long flexor tendon of the thumb approximately one year after surgery; also, in this case, the suspicion falls on a surgical technique error. ${ }^{26}$ It is documented that the implantation of the distal radius volar plate too distal to the watershed line can lead to excessive impingement with this tendon during its sliding and the risk of consequent degeneration and rupture. This complication is documented following the implantation of volar plates for distal radius also in other materials. ${ }^{30,31}$

The case described by Merolli et al. is different. ${ }^{12}$ The female patient came to attention about 11 months after ORIF with a PEEK-reinforced-carbon fiber plate for distal radius, complaining of swelling, pain, functional limitation of the wrist, and a complete loss of active flexion of three fingers. The intra-operative inspection showed an aggressive erosive flexor tendons synovitis with eroded stumps of flexor tendons; histopathology showed granulomatous fibrogenic process with multinucleated giant cells. The plate was intact and well-positioned and the fracture healed. However, in the soft tissues, many carbon fibers debris were dispersed, which triggered the inflammatory process. A detailed electron microscope analysis of the plate allowed us to assess the source: fibers were unmasked and disrupted. Inside the holes where screws were tightened. It is correct to think that the cause of the adverse event was not found in a defect in the carbon plates but in the coating of that specific plate. This case report, unique for the complication described, draws attention to the risk of release of carbon fibers, rare but possible, due to lesions of the device's coating during its implantation or coating manufacturing defects.

Di Maggio et al. reported 1 case of implant mobilization at 5 months on 64 cases. The authors of this article think that aseptic loosening of the implant is a complication linked to an error in surgical technique rather than a correlation with the implanted devices. ${ }^{15}$

Tarallo et al. reported 5 cases of plate rupture on 110 patients studied, among which four were intra-operative and one occurred 30 days after surgery subsequently to the patient falling on his wrist. ${ }^{26}$ The authors of that article believe it is "due to technical mistakes caused by lack of experience using this plate.” Tarallo et al. reported a high incidence of complications (8\%) and the most frequent complication was represented by intraoperative plate rupture (4\%). This seems to be excessive if we compare it with the percentages present in the other studies. Patients treated with first plate models still to be perfected were likely included. This would explain the high incidence of rupture during implantation, which is not found in other studies. It would have been interesting to submit the broken plates to biomechanical and metallurgical analysis to understand the exact mechanism. Afterward, Allemann et al. experienced intra-operative rupture of screw heads in 2 cases that did not lead to any complications. ${ }^{29}$ Material rupture is not usually described among complications in distal radius fractures fixation with a volar plate. We might hypothesize that this easier implant breakage might be linked to significant weakness to deformation and lower load to failure of CFR-PEEK compared to traditional plates. ${ }^{32-35}$

We found no significant differences in the other papers analyzed compared to the more widely used devices.

Three authors reported the average healing time, which is in line with what has been experimented with other devices, about 5 weeks. ${ }^{15,26,27}$ There have also been no documented periosteal reactions compatible with the biological interference of the material used. Three authors also reported the mean surgical time, which is not particularly higher than that routinely experienced in 2 cases. ${ }^{15,29}$ While the time reported by Behrendt et al. appears to be higher than that generally used for this procedure, even double (101 minutes on average). ${ }^{23}$ We are convinced that this is due to the surgeon's experience, as the surgical technique of PEEK-reinforced-carbon fiber devices for distal radius does not differ particularly from what is already in use with titanium implants. Clinical evaluations conducted using scoring scales met the expected results, in line with literature on other devices applied to the distal radius. In particular, 3 authors used the DASH scale (2 DASH and 1 Quick-DASH), and 2 authors the Mayo-Wrist Score. ${ }^{15,21,23,27}$ The current literature lacks long-term follow-up studies comparing ORIF with volar PEEK-reinforced-carbon fiber plates and the more widely used titanium plates.

\section{CONCLUSION}

PEEK-reinforced-carbon fiber distal radius plates are potentially an alternative to traditional ones. These plates are radiolucent, low profile, and lightweight. As such, they do not interfere with CT and MRI. If properly implanted, they do not significantly increase the risk of local complications, as happens if the protective layer is damaged due to incorrect use. The data collected from our review highlights how CFR-PEEK plates can represent a valid fixation device for wrist fractures. However, the literature on this subject is still poor. Comparative studies with traditional plates are few and with a limited number of patients enrolled.

Furthermore, the evolution in the production of these devices does not allow the comparison of different models. The risk of breaking with widespread tendon damage limits, in our opinion, the PEEK-reinforced-carbon fiber plates use. On the one hand, the carbon plates offer the advantage of radio transparency and lightness. On the other hand, they have higher costs and a greater risk of local complications. Therefore, their stay in the body is not recommended in the long term, and they must be removed when the fracture heals (or within 12 months), especially in young subjects. Comparative and case studies with a more significant num- 
ber of patients will clarify these doubts in the future.

\section{AUTHORS’ CONTRIBUTIONS}

Lorenzo Rocchi designed the study. Michela Saracco, Calogero Velluto and Camillo Fulchignoni were responsible for data collection. Lorenzo Rocchi and Michela Saracco contributed to the interpretation of data. Lorenzo Rocchi, Michela Saracco, and Camillo Fulchignoni drafted the manuscript. All authors critically revised the manuscript. All authors read and approved the final manuscript. Each author believes that the manuscript represents honest work.
FUNDING

This research received no grant from any funding agency.

\section{CONFLICT OF INTEREST}

The authors declare that they have no conflict of interest.

AVAILABILITY OF DATA AND MATERIAL

Electronic literature research carried out on PubMed, Google Scholars, and Cochrane Library.

Submitted: September 01, 2021 EST, Accepted: September 17, 2021 EST 


\section{REFERENCES}

1. Barrett JA, Baron JA, Karagas MR. Fracture risk in the U.S. Medicare population. J Clin Epidemiol. 1999;52(3):243-249. doi:10.1016/s0895-4356(98)0016 $\underline{7-\mathrm{X}}$

2. Wei J, Yang TB, Luo W, Qin JB, Kong FJ. Complications following dorsal versus volar plate fixation of distal radius fracture: a meta-analysis. J Int Med Res. 2013;41(2):265-275. doi:10.1177/030006051 3476438

3. Ruckenstuhl P, Bernhardt GA, Sadoghi P, et al. Quality of life after volar locked plating: a 10-year follow-up study of patients with intra-articular distal radius fractures. BMC Musculoskelet Disord. 2014;15(1):250. doi:10.1186/1471-2474-15-250

4. Boyd LG, Horne JG. The outcome of fractures of the distal radius in young adults. Injury. 1988;19(2):97-107. doi:10.1016/0020-1383(88)9008 $\underline{2-4}$

5. Orbay J. Volar plate fixation of distal radius fractures. Hand Clin. 2005;21(3):347-354. doi:10.101 6/j.hcl.2005.02.003

6. Soong M, van Leerdam R, Guitton TG. Fracture of the distal radius: risk factors for complications after locked volar plate fixation. J Hand Surg Am. 2011;36(1):3-9. doi:10.1016/j.jhsa.2010.09.033

7. McQueen M, Caspers J. Colles fracture: does the anatomical result affect the final function? J Bone Joint Surg Br. 1988;70-B(4):649-651. doi:10.1302/030 1-620x.70b4.3403617

8. Mugnai R, Tarallo L, Capra F. Biomechanical comparison between stainless steel, titanium and carbon-fiber reinforced polyetheretherketone volar locking plates for distal radius fractures. Orthop Traumatol Surg Res. 2018;104(6):877-882. doi:10.101 6/j.otsr.2018.05.002

9. Li CS, Vannabouathong C, Sprague S. The use of carbon fiber-reinforced (CFR) PEEK material in orthopedic implants: a systematic review. Clin Med Insights Arthritis Muculoskelet Disord. 2015;23:33-45. doi:10.4137/cmamd.s20354

10. Hak DJ, Mauffrey C, Seligson D, Lindeque B. Use of carbon-fiber-reinforced composite implants in orthopedic surgery. Orthopedics.

2014;37(12):825-830. doi:10.3928/01477447-2014112 4-05
11. Merolli A, Rocchi L. A discussion on the limits of carbon-fibres reinforced polymers prompted by a case of destruent synovitis in the wrist. Injury. 2015;46(4):770-771. doi:10.1016/j.injury.2014.12.011

12. Merolli A, Rocchi L, De Spirito M, et al. Debris of carbon-fibers originated from a CFRP (pEEK) wristplate triggered a destruent synovitis in human. $J$ Mater Sci: Mater Med. 2016;27(3):50. doi:10.1007/s10 856-015-5664-3

13. Wexler P. Encyclopedia of Toxicology. Elsevier; 2005.

14. Tayton K, Phillips G, Ralis Z. Long-term effects of carbon fibre on soft tissues. J Bone Joint Surg. 1982;64-B(1):112-114. doi:10.1302/0301-620x.64b1.7 $\underline{068711}$

15. Di Maggio B, Sessa P, Mantelli P, et al. PEEK radiolucent plate for distal radius fractures: multicentre clinical results at 12 months follow up. Injury. 2017;48:S34-S38. doi:10.1016/s0020-1383(1 7)30655-1

16. Rosenthall L. Radiophosphate visualization of the foreign body reaction to wear debris from total knee prosthesis. J Nucl Med. 1987;28(5):915-917.

17. Meister K, Cobb A, Bentley G. Treatment of painful articular cartilage defects of the patella by carbon-fibre implants. J Bone Joint Surg Br. 1998;80-B(6):965-970. doi:10.1302/0301-620x.80b6.0 $\underline{800965}$

18. Togawa D, Bauer TW, Brantigan JW, Lowery GL. Bone graft incorporation in radiographically successful human intervertebral body fusion cages. Spine. 2001;26(24):2744-2750. doi:10.1097/0000763 2-200112150-00025

19. Field RE, Rajakulendran K, Eswaramoorthy VK, Rushton N. Three-year prospective clinical and radiological results of a new flexible horseshoe acetabular cup. Hip Int. 2012;22(6):598-606. doi:10.53 01/hip.2012.10291

20. Tarallo L, Giorgini A, Catani F. Volar PEEK plate for distal radial fracture: analysis of plate ruptures in a group of 120 patients. J Hand Surg Eur. 2019;44(9):983-984. doi:10.1177/1753193419865124 
21. Perugia D, Guzzini M, Mazza D, Iorio C, Civitenga C, Ferretti A. Comparison between Carbon-Peek volar locking plates and titanium volar locking plates in the treatment of distal radius fractures. Injury. 2017;48:S24-S29. doi:10.1016/s0020-1383(17)3065 $\underline{3-8}$

22. Liberati A, Altman DG, Tetzlaff J, et al. The PRISMA statement for reporting systematic reviews and meta-analyses of studies that evaluate health care interventions: explanation and elaboration. $J$ Clin Epidemiol. 2009;62(10):e1-e34. doi:10.1016/i.jclin epi.2009.06.006

23. Behrendt P, Kruse E, Klüter T, et al. Fixed angle carbon fiber reinforced polymer composite plate for treatment of distal radius fractures: pilot study on clinical applications. Unfallchirurg.

2017;120(2):139-146. doi:10.1007/s00113-015-0088-6

24. Tarallo L, Mugnai R, Adani R, Catani F. A new volar plate DiPhos-RM for fixation of distal radius fracture: preliminary report. Tech Hand Up Extrem Surg. 2013;17(1):41-45. doi:10.1097/bth.0b013e31827 $\underline{700 \mathrm{bc}}$

25. Tarallo L, Mugnai R, Adani R, Zambianchi F, Catani F. A new volar plate made of carbon-fiberreinforced polyetheretherketone for distal radius fracture: analysis of 40 cases. J Orthop Traumatol. 2014;15(4):277-283. doi:10.1007/s10195-014-0311-1

26. Tarallo L, Giorgini A, Novi M, Zambianchi F, Porcellini G, Catani F. Volar PEEK plate for distal radius fracture: analysis of adverse events. Eur J Orthop Surg Traumatol. 2020;30(7):1293-1298. doi:1 0.1007/s00590-020-02701-7

27. Guzzini M, Princi G, Proietti L, Ferretti A. The use of Carbon-Peek volar plate after distal radius osteotomy for Kienbock's Disease in a volleyball athlete: a case report. Acta Biomed. 2019;90(12-S):152-155. doi:10.23750/abm.v90i12-S.8 $\underline{828}$
28. Jayakumar P, Teunis T, Giménez BB, Verstreken F, Di Mascio L, Jupiter J. AO Distal Radius Fracture Classification: Global Perspective on Observer Agreement. J Wrist Surg. 2017;6(1):46-53. doi:10.105 5/s-0036-1587316

29. Allemann F, Halvachizadeh S, Rauer T, Pape HC. Clinical outcomes after carbon-plate osteosynthesis in patients with distal radius fractures. Patient Saf Surg. 2019;13(1):30. doi:10.1186/s13037-019-0210-8

30. Yamak K, Karahan HG, Karatan B, Kayalı C, Altay T. Evaluation of Flexor Pollicis Longus Tendon Rupture after Treatment of Distal Radius Fracture with the Volar Plate. J Wrist Surg. 2020;9(3):219-224. doi:10.1055/s-0040-1702931

31. Sato K, Murakami K, Mimata Y, Doita M. Incidence of tendon rupture following volar plate fixation of distal radius fractures: A survey of 2787 cases. J Orthop. 2018;15(1):236-238. doi:10.1016/i.jo r.2018.01.030

32. Seigerman D, Lutsky K, Fletcher D, et al. Complications in the Management of Distal Radius Fractures: How Do We Avoid them? Curr Rev Musculoskelet Med. 2019;12(2):204-212. doi:10.1007/s 12178-019-09544-8

33. Pidgeon TS, Casey P, Baumgartner RE, Ferlauto H, Ruch DS. Complications of Volar Locked Plating of Distal Radius Fractures: A Prospective Investigation of Modern Techniques. Hand (New York, NY). 2020;15(5):698-706. doi:10.1177/1558944719828001

34. Alter TH, Ilyas AM. Complications Associated with Volar Locking Plate Fixation of Distal Radial Fractures. JBJS Rev. 2018;6(10):e7. doi:10.2106/jbjs.rv w.18.00004

35. Wilson J, Viner JJ, Johal KS, Woodruff MJ. Volar Locking Plate Fixations for Displaced Distal Radius Fractures: An Evaluation of Complications and Radiographic Outcomes. Hand (New York, NY). 2018;13(4):466-472. doi:10.1177/1558944717717505 